Original Article

\title{
Clinical features of patients diagnosed with degenerative rotator cuff tendon disease: a 6-month prospective-definitive clinical study from turkey
}

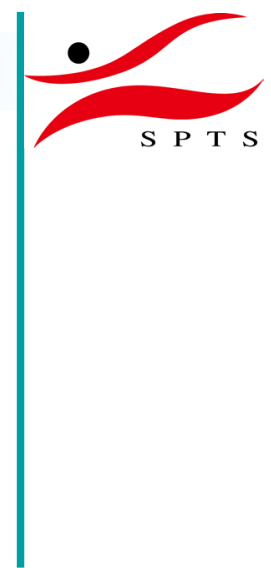

\author{
Tuba Tülay Koca, MD ${ }^{1 *}$, Aydin Arslan, MD²), Filiz ÖZdemir ${ }^{3)}$, GÜnseli Acet, MD ${ }^{1)}$ \\ 1) Physical Medicine and Rehabilitation Clinic, Research and Training Hospital: Malatya, Turkey \\ 2) Orthopedics and Traumatology Clinic, Research and Training Hospital, Turkey \\ 3) Department of Physical Medicine and Rehabilitation, Inonu University, Turkey
}

\begin{abstract}
Purpose] In rotator cuff tendon disease (RCTD), anamnesis is as important as clinical findings and anatomic/radio diagnostic examination. This study aimed to investigate the clinical features of patients diagnosed with RCTD using clinical and radiological methods between March 2015 and August 2015 at Malatya Research and Training Hospital Physical Medicine and Rehabilitation department. [Subjects and Methods] The study included 178 patients who were diagnosed with RCTD (128 females and 50 males). A questionnaire comprising 33 questions was given to each patient. [Results] Eighty-eight of the patients (49.9\%) had an involvement on their right side, eighty-four (47.1\%) had an involvement on their left side, and 6 had bilateral involvement. Mean visual analog scale (VAS) score was found to be statistically significant in favor of female patients. A statistically significant correlation was found between educational status and VAS. The body mass index (BMI) of the female patients was found to be higher than that of the male patients. Statistically significant correlation between doing risky work and gender showed that males were at a higher risk. [Conclusion] RCDT is more seen in people who have high BMI and are at their 50s. Pain complaint and BMI were found higher in female patients. DM, thyroid and cardiac diseases were seen more in the patients who are diagnosed with RCTD relative to the healthy population. Key words: Physical therapy, Rotator cuff tendon disease, Shoulder impingement
\end{abstract}

(This article was submitted Apr. 16, 2017, and was accepted May 26, 2017)

\section{INTRODUCTION}

The most common disorder of the joint of the shoulder is degenerative rotator cuff tendon disease (RCTD). Most typical symptoms comprise pain and functional disabilities ${ }^{1}$. The most common characteristics of RCTD are pain and weakness complaints especially during external rotation and elevation. The weak correlation between symptoms and nonspecific clinical tests together with morphological disorders makes the evaluation even more complicated. The diagnosis becomes more clear by eliminating other factors that can cause this disease ${ }^{2)}$. The primary radiological imaging technique is $\mathrm{x}-\mathrm{ray}^{3)}$. The clinical examination is able to define rotator cuff tears with either magnetic resonance imaging (MRI) or ultrasonography (US). US gives better results in partial tears ${ }^{4)}$.

The progression of RCTD seems multifactorial. Two theories have been proposed to define these factors: intrinsic and extrinsic factors. Recent studies indicate a correlation between intrinsic factors (such as smoking, hypertension, obesity, cardiovascular diseases) and disease prevalence in $\mathrm{RCTD}^{3)}$.

The literature comprises many conclusive results related to the factors that influence RCTD diagnosis, follow-up, and

*Correspondence author. Tuba Tülay Koca (E-mail: tuba_baglan@yahoo.com)

(C2017 The Society of Physical Therapy Science. Published by IPEC Inc.

(c) (1) $\odot$ This is an open-access article distributed under the terms of the Creative Commons Attribution Non-Commercial No Deriva-

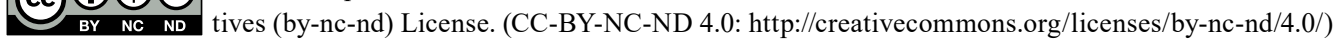


treatment. This study investigated the clinical features of patients diagnosed with RCTD using clinical and radiological methods between March 2015 and August 2015 at Malatya Research and Training Hospital Physical Medicine and Rehabilitation clinic.

\section{SUBJECTS AND METHODS}

This study was performed on patients who visited Physical Medicine and Rehabilitation clinic because of shoulder pain between March 2015 and August 2015. The study included 178 of these patients who were diagnosed with RCTD (128 females and 50 males). A questionnaire comprising 33 questions was given to each patient. In this questionnaire, age, gender, area of the shoulder pain (left/right), pain length, pain severity [(visual analog scale (VAS)], shoulder operation history, accompanying disease, trauma history, educational status, doing risky work (the work that needed repetitive movement of the shoulder), height, weight, body mass index (BMI), active shoulder movement gap, pain at night, daily intake of non-steroids, physical therapy status for the shoulder pain, number of physical therapy sessions in the last year, effect of shoulder pain on daily life, effect of shoulder pain on sleep pattern, MRI screening status, and MRI result were recorded.

SPSS version 21 (SPSS, IL, USA) was used for statistical analysis. For the demographic data, some descriptive tests were used. The normal distribution of the data was evaluated using the Kolmogorov-Smirnov test. The groups with normal distribution were evaluated using the t-test, and the groups that did not have normal distribution were evaluated using MannWhitney $\mathrm{U}$ test and $\chi^{2}$ test. A $\mathrm{p}$ value $<0.05$ was considered statistically significant.

\section{RESULTS}

Fifty male (50/28.1\%) and one hundred twenty eight female (128/71.9\%) patients were finally included in this study. Patients were told to answer all the questions. The average age of male and female patients was $48.6 \pm 18.7$ and $54.1 \pm$ 13.7 years, respectively (Table 1). Eighty-eight of the patients $(49.9 \%)$ had involvement on their right side, eighty-four (47.1\%) had involvement on their left side, and 6 had bilateral involvement. A statistically significant correlation was found between the educational status and VAS score $(\mathrm{p}=0.000)$. The pain score was found to be higher in the group who had lower educational status. The duration of the shoulder pain was between 0 and 3 months in 81 patients (45.5\%), between 3 and 6 months in 28 patients (15.7\%), between 6 months and 1 year in 22 patients (12.5), and 1 year and more in 47 patients (26.4\%). Seven patients $(3.6 \%)$ had the shoulder operation history. The number of patients who had diabetes mellitus (DM), thyroid, and cardiac diseases was $40(24.4 \%), 23(12.9 \%)$, and $42(23.5 \%)$, respectively. The number of patients who had shoulder trauma was 44 (24.7\%). The educational status of the patients is summarized in Table 2. Twenty-eight patients (15.7\%) stated that they had injection because of the shoulder pain, $106(59.6 \%)$ claimed that they used nonsteroidal anti-inflammatory drugs (NSAIDs) on a daily basis, 152 (85.4\%) also claimed that they usually had pain at night, 70 (39.3\%) said that they had MRI screening, and 137 (77\%) said that the shoulder pain influenced their sleep at night (Table 3).

In the present study, the percentage of patients who had physical therapy was $20.2 \%(\mathrm{~N}=178)$ and the percentage of patients who benefited from the physical therapy was $10.7 \%(\mathrm{~N}=58)$. In 1 year, physical therapy was given once to 19 patients, twice to 2 patients, thrice to 1 patient, 5 times to 1 patient, and 6 times to 1 patient (Table 4 ).

The mean VAS score and BMI of the male patients during 1-week period was $5.6 \pm 1.9 \mathrm{~cm}$ and $25.6 \pm 5.1 \mathrm{~kg} / \mathrm{cm}^{2}, \mathrm{respec}-$ tively. The average VAS score and BMI of the female patients during 1-week period was $6.9 \pm 1.9 \mathrm{~cm}$ and $28.6 \pm 4.3 \mathrm{~kg} / \mathrm{cm}^{2}$, respectively (Table 5). According to the Mann-Whitney $U$ test, the average VAS score was found to be statistically significant in favor of females $(\mathrm{p}=0.000)$.

The BMI of the female patients was found to be higher than that of male patients $(p=0.000)$. In addition, the statistically significant correlation between doing risky work and gender showed that males were at a higher risk $(p=0.000)$. No significant difference was found between genders in terms of shoulder pain and its effect on both daily life and sleep at night.

\section{DISCUSSION}

RCTD is characterized with the disruption of four rotator cuff muscles or more in the shoulder. The disruption of the rotator cuff also includes muscle or tendon irritation or their overuse. Since supraspinatus muscle is hidden under the acromion, most commonly the tendon of this muscle is affected. Its tears are usually seen in big tuberculous where it makes an insertion in the beginning of the humerus. Rotator cuff tendons are responsible for stabilizing glenohumeral joints, abduction, external rotation, and internal rotation. These functions can be disrupted when a trauma to the shoulder occurs ${ }^{5-7)}$.

RCTD is asymptomatic, and its prevalence increases with age. The most common cause is age-dependent degeneration. RCTD can also occur because of sport activities and trauma. Both partial tears and full-thickness defects can be seen in the MRI studies of patients who do not have shoulder pain or any symptoms. In addition, the most common complaint is shoulder pain. The complaints usually occur with overhead activities ${ }^{6-8)}$.

The unchanged risk factors of RCTD are advanced age, BMI, and height. Recurrent lifting and overhead movements increase the risk. Especially, some occupational groups (carpet makers, house painters, and construction workers) are included in this risk group. Some sportive activities such as swimming, volleyball, baseball, and tennis also increase the RCTD risk. 
Table 1. Age distribution by gender

\begin{tabular}{lr}
\hline Gender & $\mathrm{N}$, mean $\pm \mathrm{SD}$ \\
\hline Male & $50,48.6 \pm 18.7$ year \\
Female & $128,54.1 \pm 13.7$ year \\
Total & $178,52.6 \pm 15.4$ year \\
\hline
\end{tabular}

Table 3. Characteristics properties of the patients

\begin{tabular}{llc}
\hline & & $\mathrm{N} / \%$ \\
\hline \multirow{3}{*}{ Gender } & Male & $50 / 28.1$ \\
& Female & $128 / 71.9$ \\
& Total & $178 / 100$ \\
& Yes & $28 / 15.7$ \\
& No & $150 / 84.3$ \\
NSAID usage & Total & $178 / 100$ \\
& Yes & $106 / 59.6$ \\
Pain at night & No & $68 / 38.2$ \\
& Total & $174 / 100$ \\
& Yes & $152 / 85.4$ \\
MRI & To & $24 / 13.6$ \\
& Present & $176 / 100$ \\
& Absent & $70 / 39.3$ \\
Sleep effect & Total & $97 / 54.5$ \\
& Yes & $167 / 100$ \\
& No & $137 / 77$ \\
& Total & $41 / 23$ \\
\hline
\end{tabular}

MRI: magnetic resonance imaging; NSAID: nonsteroidal antiinflammatory drug
Table 2. Educational status of the patients

\begin{tabular}{lc}
\hline & $\mathrm{N} / \%$ \\
\hline Illiterate & $67 / 37.6$ \\
Primary school & $66 / 37$ \\
Elementary/High school & $37 / 20.7$ \\
University/PhD & $8 / 4.4$ \\
\hline
\end{tabular}

Table 4. Physical therapy status and its effects

\begin{tabular}{lcc}
\hline & & $\mathrm{N} / \%$ \\
\hline Physical therapy & Yes & $36 / 20.2$ \\
status & No & $142 / 79.8$ \\
& Total & $178 / 100$ \\
& 1 & $19 / 10.7$ \\
Number of physical & 2 & $2 / 1.1$ \\
therapy session & 3 & $1 / 0.6$ \\
(per a year) & 4 & $0 / 0.0$ \\
& 5 & $1 / 0.6$ \\
& 6 & $1 / 0.6$ \\
Benefit of the physical & Yes & $19 / 10.7$ \\
therapy & No & $39 / 21.9$ \\
& Total & $58 / 100$ \\
\hline
\end{tabular}

Table 5. VAS and BMI distribution by gender

\begin{tabular}{llcc}
\hline Gender & & VAS $(\mathrm{cm})$ & BMI $\left(\mathrm{kg} / \mathrm{m}^{2}\right)$ \\
\hline \multirow{2}{*}{ Male } & N, mean $\pm \mathrm{SD}$ & $50,5.6 \pm 1.9$ & $50,25.6 \pm 5.1$ \\
& Min-max & $2.0-10$ & $19.1-47.6$ \\
\multirow{2}{*}{ Female } & N, mean $\pm \mathrm{SD}$ & $128,6.9 \pm 1.9$ & $128,28.6 \pm 4.3$ \\
& Min-max & $1.0-10$ & $18.4-42.5$ \\
\multirow{2}{*}{ Total } & N, mean $\pm \mathrm{SD}$ & $178,6.6 \pm 2.0$ & $178,27.8 \pm 4.7$ \\
& Min-max & $1.00-10$ & $18.4-47.6$ \\
\hline
\end{tabular}

BMI: body mass index; VAS: visual analog scale; min: minimum; max: maximum

The etiology of the rotator cuff tears is multifactorial and it is explained by intrinsic and extrinsic theories ${ }^{7,8)}$.

The extrinsic factors include some morphological characteristics of the acromion. For example, a hooked, curved, and lateral sloping acromion has a strong correlation with RCTD and it may damage the tendon. The difference in acromial shapes can be either genetic or acquired. The other anatomic factors are os acromiale and acromial spurs. The environmental factors are advanced age, overuse, smoking, or any other clinical factor that affects inflammatory or immune response (such as $\mathrm{DM})^{7,8)}$.

The intrinsic factors include damage caused by the rotator cuff itself. The main mechanism is the degenerative-microtrauma model. Some inflammatory mediators that are released because of repetitive microtraumas disrupt the environment, and increasing oxidative stress causes $\operatorname{RCTD}^{6-8)}$.

In most of the orthopedic disorders, symptoms are correlated with the severity of the disease. It has been shown that in 
the atraumatic rotator cuff tears, anatomic features that define the severity of the disease are not correlated with the pain level ${ }^{9}$. Although radiological measurements are valid, they do not have a prognostic effect ${ }^{10}$. In atraumatic shoulder lesions, physical examination tests are more important, than medical history is not that important.

The factors that are related to pain and loss of function are not defined in patients who have tears in their rotator cuffs ${ }^{11)}$. Pain complaints are found related to comorbidities [such as cardiovascular diseases ${ }^{3)}$, DM, hypothyroidism ${ }^{12)}$, and mental health ${ }^{13)}$ ], lower educational status, and race ${ }^{14)}$. In the study by Cho et al., more pain complaints and slower recovery were observed in women than in men in the first 3 months after rotator cuff recovery ${ }^{10)}$.

Additionally, Ertan et al. reported that young age, low BMI, high functional capacity, short symptomatic period, and having reversible changes in MRI in the first evaluation were good prognostic markers in the subacromial tearing process without a rotator cuff tear ${ }^{15)}$. Rotator cuff tears mostly occur in old (more than 60 years old) and hypercholesterolemic people and during excess amount of weight lifting, working over shoulder, and using handheld devices with vibration ${ }^{16)}$.

According to the study, most of the patients diagnosed with RCTD were female in their 50s. No difference in the area of involvement was detected. The patients were in the acute phase ( $0-3$ months $)$ in terms of the duration of the pain. DM and thyroid and cardiac diseases were seen more in patients diagnosed with RCTD compared with the healthy population. The VAS score was found to be statistically higher in people who had a lower educational status.

An injection was applied to one-third of the patients because of pain compliant. Almost half of them had a trauma history. More than half of the patients needed NSAIDs daily. Most of the patients (85.4\%) had pain at night, and $77 \%$ of the patients claimed that the pain affected their sleep at night. The MRI visualization ratio was $39.4 \%$, and one-third of the patients stated that they had physical therapy. The percentage of patients who benefited from physical therapy was $10.7 \%$.

The present study showed that female patients with RCTD had more pain complaints and higher BMI. Among different occupational groups that needed repetitive shoulder movement (such as house painters and construction workers), male patients were found to be at a higher risk (because most of female patients were housewives). No difference was observed between genders in terms of the effect on daily life, disrupted sleep at night, and having MRI imaging.

Even though the prevalence of RCTD increases with age, most of the patients are asymptomatic and they do not need any surgical intervention ${ }^{11)}$. The patients with RCTD who have pain without having any loss of function are available for non-operative treatment. This treatment contains oral, anti-inflammatory agents, topical painkillers (cold pack), subacromial corticosteroids/local anesthetic injection, and physical therapy ${ }^{1,17)}$. In shoulder pain, morbidity and partial disabilities may occur $^{18)}$.

A combination of multiple treatment methods (sham therapy, radial extracorporeal shockwave therapy, steroid injection, manual therapy, acupuncture, exercise, and surgery) may work better for either subacromial impingement or nonspecific shoulder pain ${ }^{19-21)}$.

The main principles guiding the exercise program for RCTD include relative rest, modification of painful activities, exercise plan that does not increase pain, controlled weighing, and increasing shoulder movement from simple to hard. Some lifestyle changes such as education, quitting smoking, stress, and sleep control can also help in having a positive treatment response $^{3)}$. Because RCTD pathology is a broad spectrum that goes from a simple strain/injury to tendon tears, the treatment is directed at the underlying cause of the disease. Approach to the disease we suggest conservative treatment, if it fails surgery should be planned ${ }^{22}$. The percentage of patients who had surgery was $3.6 \%$, physical therapy was $20.2 \%$ and usage of NSAID was $59.6 \%$.

The present results indicated that RCTD was more seen in people who had high BMI and were in their 50s. Pain complaint and BMI were found to be higher in female patients. DM, thyroid and cardiac diseases were seen more in patients diagnosed with RCTD compared with the healthy population. Males did riskier work than females. In RCTD, anamnesis is as important as clinical findings and anatomic/radio diagnostic examination.

RCTD is one of the most important reasons behind shoulder pain and disability. A deep understanding about disease etiopathogenesis and the factors related to the course of the disease may aid tendon repair in the future.

Summarily; in RCTD, a weak correlation between symptoms and nonspecific clinical tests together with morphological disorders makes the evaluation even more complicated. So, clinical anamnesis, physical symptoms and signs are as important as radiological imagination.

\section{Conflict of interest}

There is no conflict of interest for all authors.

\section{REFERENCES}

1) Lepola V, Paloneva J, Huuskonen ML, et al. Tiivistelmä: [Update on current care guidelines. The tendon disorders of the shoulder]. Duodecim, 2015, 131: 194-195 (in Finnish). [Medline]

2) Lewis J, McCreesh K, Roy JS, et al.: Rotator cuff tendinopathy: navigating the diagnosis-management conundrum. J Orthop Sports Phys Ther, 2015, 45: 923-937. [Medline] [CrossRef]

3) Djerbi I, Chammas M, Mirous MP, et al. French Society For Shoulder and Elbow (SOFEC): Impact of cardiovascular risk factor on the prevalence and severity 
of symptomatic full-thickness rotator cuff tears. Orthop Traumatol Surg Res, 2015, 101: S269-S273. [Medline] [CrossRef]

4) Dinnes J, Loveman E, McIntyre L, et al.: The effectiveness of diagnostic tests for the assessment of shoulder pain due to soft tissue disorders: a systematic review. Health Technol Assess, 2003, 7: iii, 1-166. [Medline] [CrossRef]

5) Williams GR Jr, Rockwood CA Jr, Bigliani LU, et al.: Rotator cuff tears: why do we repair them? J Bone Joint Surg Am, 2004, 86-A: 2764-2776. [Medline] [CrossRef]

6) Harris JD, Pedroza A, Jones GL, MOON (Multicenter Orthopedic Outcomes Network) Shoulder Group: Predictors of pain and function in patients with symptomatic, atraumatic full-thickness rotator cuff tears: a time-zero analysis of a prospective patient cohort enrolled in a structured physical therapy program. Am J Sports Med, 2012, 40: 359-366. [Medline] [CrossRef]

7) Factor D, Dale B: Current concepts rotator cuff tendinopathy. Int J Sports Phys Ther, 2014, 9: 274-288.

8) Schmidt CC, Jarrett CD, Brown BT: Management of rotator cuff tears. J Hand Surg Am, 2015, 40: 399-408. [Medline] [CrossRef]

9) Dunn WR, Kuhn JE, Sanders R, et al.: Symptoms of pain do not correlate with rotator cuff tear severity: a cross-sectional study of 393 patients with a symptomatic atraumatic full-thickness rotator cuff tear. J Bone Joint Surg Am, 2014, 96: 793-800. [Medline] [CrossRef]

10) Cho CH, Ye HU, Jung JW, et al.: Gender affects early postoperative outcomes of rotator cuff repair. Clin Orthop Surg, 2015, 7: 234-240. [Medline] [CrossRef]

11) Harris JD, Pedroza A, Jones GL, MOON (Multicenter Orthopedic Outcomes Network) Shoulder Group: Predictors of pain and function in patients with symptomatic, atraumatic full-thickness rotator cuff tears: a time-zero analysis of a prospective patient cohort enrolled in a structured physical therapy program. Am J Sports Med, 2012, 40: 359-366. [Medline] [CrossRef]

12) Blonna D, Fissore F, Bellato E, et al.: Subclinical hypothyroidism and diabetes as risk factors for postoperative stiff shoulder. Knee Surg Sports Traumatol Arthrosc, 2015 [Epubahead of print]. [Medline] [CrossRef]

13) Wylie JD, Suter T, Potter MQ, et al.: Mental health has a stronger association with patient-reported shoulder pain and function than tear size in patients with full-thickness rotator cuff tears. J Bone Joint Surg Am, 2016, 98: 251-256. [Medline] [CrossRef]

14) de Witte PB, van Adrichem RA, Selten JW, et al.: Radiological and clinical predictors of long-term outcome in rotator cuff calcific tendinitis. Eur Radiol, 2016, 26: 3401-3411. [Medline] [CrossRef]

15) Ertan S, Ayhan E, Güven MF, et al.: Medium-term natural history of subacromial impingement syndrome. J Shoulder Elbow Surg, 2015, 24: 1512-1518. [Medline] [CrossRef]

16) Raynor MB, Kuhn JE: Utility of features of the patient's history in the diagnosis of atraumatic shoulder pain: a systematic review. J Shoulder Elbow Surg, 2016, 25: 688-694. [Medline] [CrossRef]

17) Mantone JK, Burkhead WZ Jr, Noonan J Jr: Nonoperative treatment of rotator cuff tears. Orthop Clin North Am, 2000, 31: 295-311. [Medline] [CrossRef]

18) Green S, Buchbinder R, Hetrick S: Physiotherapy interventions for shoulder pain. Cochrane Database Syst Rev, 2003, (2): CD004258. [Medline]

19) Goldgrub R, Côté P, Sutton D, et al.: The effectiveness of multimodal care for the management of soft tissue injuries of the shoulder: a systematic review by the Ontario Protocol for Traffic Injury Management (OPTIMa) collaboration. J Manipulative Physiol Ther, 2016, 39: 121-39.e1. [Medline] [CrossRef]

20) Yi A, Villacis D, Yalamanchili R, et al.: A comparison of rehabilitation methods after arthroscopic rotator cuff repair: a systematic review. Sports Health, 2015, 7: 326-334. [Medline] [CrossRef]

21) Hsu J, Keener JD: Natural history of rotator cuff disease and implications on management. Oper Tech Orthop, 2015, 25: 2-9. [Medline] [CrossRef]

22) Codsi M, Howe CR: Shoulder conditions: diagnosis and treatment guideline. Phys Med Rehabil Clin N Am, 2015, 26: 467-489. [Medline] [CrossRef] 